\title{
BMJ Open Governmental designation of spine specialty hospitals, their characteristics, performance and designation effects: a longitudinal study in Korea
}

\author{
Sun Jung Kim, ${ }^{1,2}$ Ji Won Yoo, ${ }^{3,4}$ Sang Gyu Lee, ${ }^{2,5}$ Tae Hyun Kim, ${ }^{2,5}$ \\ Kyu-Tae Han, ${ }^{1,2}$ Eun-Cheol Park ${ }^{2,6}$
}

To cite: Kim SJ, Yoo JW, Lee SG, et al. Governmental designation of spine specialty hospitals, their characteristics, performance and designation effects: a longitudinal study in Korea. BMJ Open 2014;4: e006525. doi:10.1136/ bmjopen-2014-006525

- Prepublication history for this paper is available online. To view these files please visit the journal online (http://dx.doi.org/10.1136/ bmjopen-2014-006525).

Received 3 September 2014 Revised 7 October 2014 Accepted 24 October 2014

CrossMark

For numbered affiliations see end of article.

Correspondence to Dr Eun-Cheol Park; ecpark@yuhs.ac

\section{ABSTRACT}

Objectives: This study compares the characteristics and performance of spine specialty hospitals versus other types of hospitals for inpatients with spinal diseases in South Korea. We also assessed the effect of the government's specialty hospital designation on hospital operating efficiency.

Setting: We used data of 823 hospitals including 17 spine specialty hospitals in Korea.

Participants: All spine disease-related inpatient claims nationwide ( $\mathrm{N}=645$ 449) during 2010-2012.

Interventions: No interventions were made.

Outcome measures: Using a multilevel generalised estimating equation and multilevel modelling, this study compared inpatient charges, length of stay (LOS), readmission within 30 days of discharge and in-hospital death within 30 days of admission in spine specialty versus other types of hospitals.

Results: Spine specialty hospitals had higher inpatient charges per day $(27.4 \%)$ and a shorter LOS $(23.5 \%)$, but per case charges were similar after adjusting for patientlevel and hospital-level confounders. After government designation, spine specialty hospitals had $8.8 \%$ lower per case charges, which was derived by reduced per day charge $(7.6 \%)$ and shorter LOS $(1.0 \%)$. Rates of readmission also were lower in spine specialty hospitals $(\mathrm{OR}=0.796)$. Patient-level and hospital-level factors both played important roles in determining outcome measures. Conclusions: Spine specialty hospitals had higher per day inpatient charges but a much shorter LOS than other types of hospitals due to their specialty volume and experience. In addition, their readmission rate was lower. Spine specialty hospitals also endeavoured to be more efficient after governmental 'specialty' designation.

\section{INTRODUCTION}

Since 1 November 2011, the Korean Ministry of Health-Welfare has designated 92 hospitals in South Korea as 'specialty hospitals' to promote specialised, high quality care. These specialty hospitals encompass specialty areas including spine, joint, colorectal-anal, burn,

\section{Strengths and limitations of this study}

- This study is one of only a few studies to evaluate the performance and characteristics of specialty hospitals in this country, where government designated the hospitals and even outside USA.

- This study used nationwide all spine-related inpatient health insurance claims, which accounted for 645449 participants.

- This study provides reasoning for designing 'specialty' designation requirements and implementing specialty hospital systems in a health policy perspective.

- The limitations of this study include lack of important patient socioeconomic status data and investigation of short-term policy effect.

breast, heart, ENT (ear, nose and throat), ophthalmology, alcohol treatment, OBGYN, neurosurgery and physical rehabilitation, etc. The highest number of hospitals with this designation (17) includes spine specialty hospitals.

Since South Korea established a national health insurance (NHI) programme in 1989, hospitals have faced many challenges such as an ageing population, rapidly rising healthcare costs and growing chronic disease burden. ${ }^{1}$ These challenges are being addressed by various policy initiatives at the government level. In addition, physicians altering the mix of treatments to increase profit margin ${ }^{2}$ and the increased level of competition among providers present incentives for increasing efficiency. ${ }^{3}$ Moreover, providers have experienced financial challenges, ${ }^{3}$ due in part to the rapid increase in small general hospitals, from 581 in 2000 to 1295 in $2010 .{ }^{4}$ In order to address these challenges, small hospitals have begun to specialise in order to better compete with small general, mid-sized general and even tertiary research hospitals. ${ }^{5}$ 
To be designated as a specialty hospital by the Korean Ministry of Health-Welfare, institutions must submit an application and be equipped with a certain number of beds, number of physicians and must have medical service departments in their specialty area. The inpatient volume of these institutions must be above the 30 th centile among all small and mid-sized general hospitals, and the ratio of specialty-area inpatients to total inpatients must be above a certain percentage depending on the specialty area.

The concept of specialty hospitals was first introduced in the USA beginning in the 1990s. The first specialty hospitals typically were located in fast-growing cities in states where a 'certificate of need' was not required. ${ }^{6}$ Subsequently, there was a rapid increase in the number of small hospitals specialising in cardiac, orthopaedic and surgical services. ${ }^{7}$ Furthermore, most of these hospitals were physician-owned, for-profit and specialty-specific. ${ }^{8}$

Proponents argue that specialty hospitals provide highquality medical services at a lower cost, ${ }^{9-11}$ bring added value to the healthcare system ${ }^{12}{ }^{13}$ and lead to greater patient satisfaction. ${ }^{14}{ }^{15}$ The increase in patient volume and concentration of expertise allows specialty hospitals to achieve better outcomes and maximise efficiency. ${ }^{16}$ However, opponents contend that specialty hospitals have lower quality and higher costs, since they are forprofit and specialise in only the most profitable services, target healthier patients who are more well-off and induce demand for their specialised services. ${ }^{17-20}$

The purpose of this study was to compare the performance of spine specialty hospitals versus other types of hospitals in South Korea where, in contrast to the physician-owned specialty hospitals in the USA, the South Korean government designates only qualified institutions as specialty hospitals, by evaluating the inpatient charge per case, inpatient charge per day, length of stay (LOS), readmission within 30 days of discharge and in-hospital deaths within 30 days of admission for patients. In addition, this study also investigated the effect of designation as a 'specialty' hospital on hospital operating efficiency.

\section{DATA AND METHODS}

\section{Database and data collection}

In order to investigate the designation effect of specialty hospitals and to measure their performance, we collected all nationwide claims for inpatients diagnosed with spine diseases from categories used to determine the spine specialty hospital designation by the Ministry of Health and Welfare. Treatments for spine-related diseases included surgical procedures (discectomy, excision of intraspinal lesion, spinal fusion with deformity, spinal fusion, amputation, radical excision of malignant bone tumour, osteotomy and external fixation of extremity, etc) and medical procedures specific to spinal disorders and injuries, osteomyelitis, connective tissue malignancy, connective tissue disorders, other musculoskeletal disorders, etc. We were able to access claims reported during the 7 months after the government began to designate specialty hospitals on 1 November 2011 (1 November 2011 to 31 May 2012) and included claims reported in the same 7-month period 1 year prior (1 November 2010 to 31 May 2011). Among nearly 1600 hospitals included in the database, only those that admitted more than one spinal-related inpatient case were included. Our analysis encompassed 645449 patients hospitalised for spine-related illnesses nationwide during the study period, and 823 hospitals including 17 spine specialty hospitals.

\section{Outcome measures}

Inpatient charges per case are the sum of fee-for-services (FFS) claims for each patient's hospitalisation. LOS is measured as the number of inpatient days during each episode of hospitalisation. We also calculated inpatient charge per day by dividing inpatient charges per case by the LOS. In Korea, the FFS schedule is negotiated by the government, medical providers and other stakeholders every year. In 2012, the FFS catalogue increased by $1.9 \%$, but there were no increases in 2010 and 2011 . Hence, we discounted 2012 inpatient charges to 2010 2011 levels. The average foreign exchange rate in 2011 was US $\$ 1=1108.09 \mathrm{KRW}$. Using the claim sample, we also calculated readmission within 30 days of discharge and mortality within 30 days of admission date as a binary variable if a patient was rehospitalised soon after discharge or died during hospitalisation.

\section{Covariates}

This data set contained inpatient claim details, including patient ID, disease diagnosed, admission/discharge date, sex, age, complexity of illness and the hospital to which each patient was admitted. Complexity of illness was measured by the provider and reported as claim data using the complication or comorbidity level (CCL; $0=$ patient does not have a complication or comorbidity (CC), 1=patient has a minor CC, 2=patient has a moderate CC, 3=patient has a complex CC) when each patient was admitted. Patient claims data were matched to the hospitals where each patient was admitted.

Hospital-level data included characteristics of the hospital, such as hospital type (specialty, tertiary, large, small), number of beds (in 100 bed increments), specialists per 100 beds, nurses per 100 beds, hospital location (metropolitan if located in cities with a population of more than one million), teaching status and bed occupancy rate. According to the Korean Hospital Association, Korean hospitals are categorised into three groupings based on bed size: (1) hospitals with over 1000 beds: tertiary research university hospitals, (2) hospitals with 300-1000 beds: mid-sized general hospitals and (3) hospitals with 100-300 beds: small general hospitals. The specialty hospitals and the small general hospitals in our study both fell within category 3 (small general hospitals). ${ }^{21}$ The hospital level data were obtained from the Agency for Health Insurance Review 
and Assessment Services. In order to investigate the post policy designation effect, we included the interaction term of type of hospital and year, which we named designation effect.

We also included data envelopment analysis (DEA) using efficiency as the dummy variable ( $1=$ efficient, $0=$ nonefficient) to determine whether hospitals were operated efficiently using a conventional technical efficiency measuring technique. ${ }^{22}$ It is derived from microeconomics methodology where input and output combinations are depicted using a production function to measure the efficiency of multiple decision-making units (in this case hospitals) when the production process presents a structure of multiple inputs and outputs. ${ }^{22}$ Input variables included number of beds, surgical beds, recovery beds, specialists, residents, nurses, physical therapists and pharmacists; and positron emission tomography, CT and MRI units of each hospital. Output variables included total number of inpatient cases and sum of charges in 2011 and 2012 study periods for each hospital. Hospital-level statistics were collected based on their first quarter of 2012 status, which was the only available data set at the time of this study.

\section{Analytical approach}

Mean and SD were analysed for continuous variables; frequency and per cent were analysed for categorical variables. Univariate analysis of inpatient charges, LOS, readmission within 30 days of discharge and mortality within 30 days of admission was performed to investigate the unadjusted effects of hospital types on these measures. Analysis of variance and $\chi^{2}$ tests were performed for identification of group differences. Because the unit of analysis was each patient's hospitalisation, this study utilised multilevel generalised estimating equation (GEE) regression models in order to avoid problems created by possible nesting of patient observations in hospitals and overestimation of significance.

The GEE regression models were used to investigate the performance and characteristics of specialty hospitals, including inpatient charges, LOS, readmission and mortality adjusting for patient-level and hospital-level confounders. Because the distributions of continuous dependent variables (inpatient charges and LOS) were skewed, we utilised log transformation in order to improve the distribution characteristics of the data. In addition, we ran the GEEs of the binary outcome variables for readmission within 30 days of discharge and mortality within 30 days of admission. In order to enhance case mix adjustment, we included the diagnosis and procedure code in each model. SAS V.9.2 (SAS Institute, Cary, North Carolina, USA) was used for all calculations and analyses. As the data set does not have patient identification information, no ethics committee approval is required.

\section{RESULTS}

A total of 645449 patients nationwide were hospitalised for spinal disease during the study periods, and 17 specialty hospitals accounted for 45649 (7.1\%) of patients nationwide admitted for spine disease (table 1). Patients in spine specialty hospitals were aged and female, had undergone more surgical procedures, and had lower CCL scores. The increase in volume in 2012 compared with 2011 was greater than average in specialty hospitals as well as in conventional hospitals (total: $12.9 \%$ vs specialty $17.8 \%$ ).

Table 2 shows the hospital characteristics analysed. Of the 823 hospitals in our study, there were 17 Ministry of Health and Welfare-designated spine specialty hospitals (2.1\% of the total), which accounted for $7.1 \%$ of the total spinal procedures performed nationwide during the study period. While none of these was a teaching hospital, they were located mainly in metropolitan areas, and their structural factors were greater in terms of number of beds (in 100 bed increments), specialists per 100 beds and nurses per 100 beds as well as bed occupancy rate as compared with hospitals in the small general hospital category. Although specialty hospitals are larger than small general hospitals in terms of structural factors, both types of hospitals fall within the same small hospital category in Korea. Clinical staff was greater in spine specialty hospitals than in mid-sized general hospitals. Furthermore, $11.8 \%$ of specialty hospitals were considered to be efficient compared with $6.8 \%$ of all hospitals.

Univariate analysis of outcome variables (see table 3) revealed that inpatient charges per case were lowest in spine specialty hospitals; however, per day charges were higher than in small and mid-sized general hospitals. LOS was 10.9 days per admission, which was comparable with tertiary research hospitals, but was much shorter than in small and mid-sized general hospitals. Readmission within 30 days of discharge was much lower for the spine specialty hospitals than for other hospital types. Death within 30 days of admission also was lowest in specialty hospitals; however, cases of death were very rare in all types of hospitals because spinal procedures typically are not based on life-threatening conditions. Lower charges per case, charges per day and reduced LOS were observed among specialty hospitals during the postdesignation period.

The results of our multilevel GEE regression analysis are presented in table 4 . Although spine specialty hospitals had a $2.8 \%$ higher inpatient charge per case than small general hospitals, the difference was not statistically significant. An effect of the official 'specialty' designation was found with regard to inpatient charge per case, with charges per case decreasing $8.8 \%$ after specialty status was conferred. Spine specialty hospitals charged an average of $27.4 \%$ more than small general hospitals on a per-day basis, although the LOS at spine specialty hospitals was $23.5 \%$ shorter. Moreover, charges per case decreased $7.6 \%$ and LOS was reduced by $1 \%$ after specialty status was conferred. The OR of readmission was $\mathrm{OR}=0.796$ for the spine specialty hospitals compared with small general hospitals; however, the ORs of 
Table 1 Characteristics of patients

\begin{tabular}{|c|c|c|c|c|c|c|c|c|c|c|c|}
\hline & \multicolumn{2}{|l|}{ Total } & \multicolumn{2}{|c|}{ Specialty hospital } & \multicolumn{2}{|c|}{ Tertiary hospital } & \multicolumn{2}{|c|}{ Mid-sized hospital } & \multicolumn{2}{|c|}{ Small hospital } & \multirow[b]{2}{*}{ p Value } \\
\hline & N/mean & $\% / S D$ & N/mean & $\% / S D$ & N/mean & $\% / S D$ & N/mean & $\% / S D$ & N/mean & $\% / S D$ & \\
\hline Number of cases & 645449 & & 45649 & 7.1 & 132972 & 20.6 & 208431 & 32.3 & 258397 & 40.0 & \\
\hline $\mathrm{Age}^{\star}$ & 52.6 & 19.7 & 55.8 & 15.5 & 47.3 & 23.0 & 53.5 & 20.5 & 54.1 & 17.1 & $<0.0001$ \\
\hline \multicolumn{12}{|l|}{ Sex } \\
\hline Male & 292744 & 45.4 & 20795 & 45.6 & 62981 & 47.4 & 98715 & 47.4 & 110253 & 42.7 & $<0.0001$ \\
\hline Female & 352705 & 54.6 & 24854 & 54.4 & 69991 & 52.6 & 109716 & 52.6 & 148144 & 57.3 & \\
\hline \multicolumn{12}{|l|}{ Year } \\
\hline Predesignation & 303220 & 47.0 & 20956 & 45.9 & 64173 & 48.3 & 100647 & 48.3 & 117444 & 45.5 & $<0.0001$ \\
\hline Postdesignation & 342229 & 53.0 & 24693 & 54.1 & 68799 & 51.7 & 107784 & 51.7 & 140953 & 54.5 & \\
\hline $\begin{array}{l}{ }^{*} \text { Volume increase in } \\
\text { postdesignation }\end{array}$ & $12.9 \%$ & & $17.8 \%$ & & $7.2 \%$ & & $7.1 \%$ & & $20.0 \%$ & & \\
\hline \multicolumn{12}{|l|}{ CCL score } \\
\hline 0 & 436621 & 67.6 & 32190 & 70.5 & 93631 & 70.4 & 124595 & 59.8 & 186205 & 72.1 & $<0.0001$ \\
\hline 1 & 140158 & 21.7 & 9897 & 21.7 & 24330 & 18.3 & 51641 & 24.8 & 54290 & 21.0 & \\
\hline 2 & 56346 & 8.7 & 3114 & 6.8 & 11974 & 9.0 & 25939 & 12.4 & 15319 & 5.9 & \\
\hline 3 & 12324 & 1.9 & 448 & 1.0 & 3037 & 2.3 & 6256 & 3.0 & 2583 & 1.0 & \\
\hline \multicolumn{12}{|l|}{ Procedure type } \\
\hline Surgical & 579853 & 89.8 & 45386 & 99.4 & 101431 & 76.3 & 185151 & 88.8 & 247885 & 95.9 & $<0.0001$ \\
\hline Medical & 65596 & 10.2 & 263 & 0.6 & 31541 & 23.7 & 23280 & 11.2 & 10512 & 4.1 & \\
\hline
\end{tabular}

*Mean/SD

$\mathrm{CCL}$, complication or comorbidity level.

\begin{tabular}{|c|c|c|c|c|c|c|c|c|c|c|c|}
\hline & \multicolumn{2}{|l|}{ Total } & \multicolumn{2}{|c|}{$\begin{array}{l}\text { Specialty } \\
\text { hospital }\end{array}$} & \multicolumn{2}{|c|}{ Tertiary hospital } & \multicolumn{2}{|c|}{$\begin{array}{l}\text { Mid-sized } \\
\text { hospital }\end{array}$} & \multicolumn{2}{|c|}{ Small hospital } & \multirow[b]{2}{*}{ p Value } \\
\hline & N/mean & $\% / S D$ & N/mean & $\% / S D$ & N/mean & $\% / S D$ & N/mean & $\% / S D$ & N/mean & $\% / S D$ & \\
\hline Number of hospitals* & 823 & & 17 & 2.1 & 44 & 5.3 & 267 & 32.4 & 495 & 60.1 & \\
\hline \multicolumn{12}{|l|}{ Geographic } \\
\hline Metropolitan area & 439 & 53.3 & 14 & 82.4 & 33 & 75.0 & 129 & 48.3 & 263 & 53.1 & \multirow[t]{2}{*}{0.001} \\
\hline Non-metropolitan area & 384 & 46.7 & 3 & 17.6 & 11 & 25.0 & 138 & 51.7 & 232 & 46.9 & \\
\hline \multicolumn{12}{|l|}{ Teaching status } \\
\hline Teaching & 149 & 18.1 & - & 0.0 & 44 & 100.0 & 102 & 38.2 & 3 & 0.6 & \multirow[t]{2}{*}{$<0.0001$} \\
\hline Non-teaching & 674 & 81.9 & 17 & 100.0 & - & 0.0 & 165 & 61.8 & 492 & 99.4 & \\
\hline \multicolumn{12}{|l|}{ DEA efficiency } \\
\hline Efficient & 56 & 6.8 & 2 & 11.8 & - & 0.0 & 3 & 1.1 & 51 & 10.3 & \multirow[t]{2}{*}{$<0.0001$} \\
\hline Non-efficient & 767 & 93.2 & 15 & 88.2 & 44 & 100.0 & 264 & 98.9 & 444 & 89.7 & \\
\hline Number of beds $(\times 100)^{\star}$ & 4.5 & 4.8 & 1.4 & 0.6 & 11.7 & 5.5 & 4.4 & 2.1 & 1.3 & 0.7 & $<0.0001$ \\
\hline Number of specialists per 100 beds* & 14.7 & 8.1 & 15.7 & 5.6 & 25.9 & 7.1 & 13.7 & 5.4 & 9.5 & 4.0 & $<0.0001$ \\
\hline Number of nurses per 100 beds $^{*}$ & 50.3 & 24.2 & 60.0 & 23.9 & 74.1 & 16.9 & 54.8 & 19.7 & 32.7 & 16.2 & $<0.0001$ \\
\hline Bed occupancy rate* & 85.2 & 16.9 & 83.0 & 10.5 & 98.7 & 9.1 & 85.5 & 13.6 & 78.5 & 19.1 & $<0.0001$ \\
\hline
\end{tabular}


Table 3 Univariate analysis of dependent variables by hospital types

\begin{tabular}{|c|c|c|c|c|c|c|c|c|c|c|c|c|c|c|}
\hline & \multicolumn{7}{|c|}{ Specialty hospital } & \multicolumn{7}{|c|}{ Tertiary hospital } \\
\hline & \multicolumn{2}{|c|}{ Total } & \multicolumn{2}{|c|}{ Predesignation } & \multicolumn{2}{|c|}{ Postdesignation } & \multirow[b]{2}{*}{ p Value } & \multicolumn{2}{|c|}{ Total } & \multicolumn{2}{|c|}{ Predesignation } & \multicolumn{2}{|c|}{ Postdesignation } & \multirow[b]{2}{*}{ p Value } \\
\hline & N/mean & $\% / S D$ & N/mean & $\% / S D$ & $\mathrm{~N} / \mathrm{mean}$ & $\% / S D$ & & N/mean & $\% / S D$ & N/mean & $\% / S D$ & $\mathrm{~N} / \mathrm{mean}$ & $\% / S D$ & \\
\hline Charges per case $(\mathrm{KRW})^{\star}$ & 2357468 & 1619618 & 2375527 & 1550231 & 2342143 & 1676132 & 0.028 & 3059806 & 2688264 & 2856209 & 2289087 & 3249713 & 3000898 & $<0.0001$ \\
\hline Charges per day $(\mathrm{KRW})^{\star}$ & 251661 & 150845 & 252214 & 164000 & 251191 & 138707 & 0.471 & 323255 & 231344 & 311785 & 223778 & 333953 & 237687 & $<0.0001$ \\
\hline Length of stay (days) ${ }^{*}$ & 10.9 & 7.3 & 11.2 & 7.7 & 10.6 & 7.0 & $<0.0001$ & 10.6 & 9.2 & 10.7 & 9.4 & 10.5 & 9.1 & $<0.0001$ \\
\hline \multicolumn{15}{|c|}{$\begin{array}{l}\text { Readmission within } 30 \text { days of } \\
\text { discharge }\end{array}$} \\
\hline Yes & 505 & $1.11 \%$ & 234 & $1.12 \%$ & 271 & $1.10 \%$ & 0.846 & 9275 & $6.98 \%$ & 4408 & $6.87 \%$ & 4867 & $7.07 \%$ & 0.142 \\
\hline No & 45144 & $98.89 \%$ & 20722 & $98.88 \%$ & 24422 & $98.90 \%$ & & 123697 & $93.02 \%$ & 59765 & $93.13 \%$ & 63932 & $92.93 \%$ & \\
\hline \multicolumn{15}{|c|}{$\begin{array}{l}\text { In-hospital death within } 30 \text { days } \\
\text { of admission }\end{array}$} \\
\hline Yes & 1 & $0.00 \%$ & 1 & $0.005 \%$ & - & $0.0 \%$ & 0.278 & 352 & $0.26 \%$ & 172 & $0.27 \%$ & 180 & $0.26 \%$ & 0.821 \\
\hline \multirow[t]{4}{*}{ No } & 45648 & $100.00 \%$ & 20955 & $99.995 \%$ & 24693 & $100.0 \%$ & & 132620 & $99.74 \%$ & 64001 & $99.73 \%$ & 68619 & $99.74 \%$ & \\
\hline & \multicolumn{7}{|c|}{ Mid-sized hospital } & \multicolumn{7}{|c|}{ Small hospital } \\
\hline & \multicolumn{2}{|c|}{ Total } & \multicolumn{2}{|c|}{ Predesignation } & \multicolumn{2}{|c|}{ Postdesignation } & & \multicolumn{2}{|c|}{ Total } & \multicolumn{2}{|c|}{ Predesignation } & \multicolumn{2}{|c|}{ Postdesignation } & \\
\hline & N/mean & $\% / S D$ & N/mean & $\% / S D$ & N/mean & $\% / S D$ & p Value & N/mean & $\% / S D$ & N/mean & $\% / S D$ & N/mean & $\% / S D$ & p Value \\
\hline Charges per case $(\mathrm{KRW})^{*}$ & 3028064 & 2352461 & 2891420 & 2082341 & 3155660 & 2572744 & $<0.0001$ & 2559995 & 2170122 & 2479704 & 2050050 & 2626895 & 2263145 & $<0.0001$ \\
\hline Charges per day $(\mathrm{KRW})^{\star}$ & 234173 & 178011 & 229703 & 182652 & 238347 & 173462 & $<0.0001$ & 246804 & 180053 & 245242 & 190559 & 248106 & 170796 & $<0.0001$ \\
\hline Length of stay (days) ${ }^{\star}$ & 15.5 & 12.2 & 15.6 & 12.2 & 15.4 & 12.1 & $<0.0001$ & 12.5 & 9.3 & 12.6 & 9.5 & 12.4 & 9.2 & $<0.0001$ \\
\hline \multicolumn{15}{|c|}{$\begin{array}{l}\text { Readmission within } 30 \text { days of } \\
\text { discharge }\end{array}$} \\
\hline Yes & 5761 & $2.76 \%$ & 2814 & $2.80 \%$ & 2947 & $2.73 \%$ & 0.390 & 4024 & $1.56 \%$ & 1880 & $1.60 \%$ & 2144 & $1.52 \%$ & 0.103 \\
\hline No & 202670 & $97.24 \%$ & 97833 & $97.20 \%$ & 104837 & $97.27 \%$ & & 254373 & $98.44 \%$ & 115564 & $98.40 \%$ & 138809 & $98.48 \%$ & \\
\hline \multicolumn{15}{|c|}{$\begin{array}{l}\text { In-hospital death within } 30 \text { days of } \\
\text { admission }\end{array}$} \\
\hline Yes & 432 & $0.21 \%$ & 197 & $0.196 \%$ & 235 & $0.2 \%$ & 0.263 & 95 & $0.04 \%$ & 38 & $0.03 \%$ & 57 & $0.04 \%$ & 0.286 \\
\hline No & 207999 & $99.79 \%$ & 100450 & $99.804 \%$ & 107549 & $99.8 \%$ & & 258302 & $99.96 \%$ & 117406 & $99.97 \%$ & 140896 & $99.96 \%$ & \\
\hline
\end{tabular}




\begin{tabular}{|c|c|c|c|c|c|c|c|c|c|c|}
\hline & \multicolumn{2}{|c|}{ In_Charges per case } & \multicolumn{2}{|c|}{ In_Charges per day } & \multicolumn{2}{|l|}{ In_LOS } & \multicolumn{2}{|c|}{$\begin{array}{l}\text { Readmission } \\
\text { within } 30 \text { days } \\
\text { of discharge }\end{array}$} & \multicolumn{2}{|c|}{$\begin{array}{l}\text { In-hospital death } \\
\text { within } 30 \text { days of } \\
\text { admission }\end{array}$} \\
\hline & Estimation (\%) & p Value & Estimation (\%) & p Value & Estimation (\%) & p Value & $\overline{\text { OR }}$ & p Value & OR & p Value \\
\hline \multicolumn{11}{|l|}{ Patient level } \\
\hline Age & 0.002 & $<0.0001$ & 0.001 & $<0.0001$ & 0.001 & $<0.0001$ & 0.995 & $<0.0001$ & 1.030 & $<0.0001$ \\
\hline \multicolumn{11}{|l|}{ Sex } \\
\hline Male & 0.015 & $<0.0001$ & 0.040 & $<0.0001$ & -0.025 & $<0.0001$ & 0.938 & $<0.0001$ & 1.245 & 0.002 \\
\hline Female & Ref. & & & & & & & & & \\
\hline \multicolumn{11}{|l|}{ CCL score } \\
\hline 1 & 0.181 & $<0.0001$ & -0.038 & $<0.0001$ & 0.218 & $<0.0001$ & 1.127 & $<0.0001$ & 4.097 & $<0.0001$ \\
\hline 2 & 0.314 & $<0.0001$ & -0.001 & 0.574 & 0.315 & $<0.0001$ & 1.009 & 0.758 & 22.218 & $<0.0001$ \\
\hline 3 & 0.533 & $<0.0001$ & 0.064 & $<0.0001$ & 0.469 & $<0.0001$ & 1.264 & $<0.0001$ & 185.824 & $<0.0001$ \\
\hline 0 & Ref. & & & & & & & & & \\
\hline \multicolumn{11}{|l|}{ Year } \\
\hline 2012 & 0.068 & $<0.0001$ & 0.072 & $<0.0001$ & -0.004 & 0.143 & 0.987 & 0.699 & 1.250 & 0.292 \\
\hline 2011 & Ref. & & & & & & & & & \\
\hline \multicolumn{11}{|l|}{ Hospital level } \\
\hline \multicolumn{11}{|l|}{ Hospital type } \\
\hline Specialty hospital & 0.028 & 0.605 & 0.274 & $<0.0001$ & -0.235 & $<0.0001$ & 0.796 & 0.002 & 0.295 & 0.230 \\
\hline Tertiary hospital & 0.313 & $<0.0001$ & 0.479 & $<0.0001$ & -0.138 & 0.036 & 1.005 & 0.918 & 1.380 & 0.172 \\
\hline Mid-sized hospital & 0.229 & $<0.0001$ & 0.175 & $<0.0001$ & 0.067 & 0.007 & 0.971 & 0.465 & 1.399 & 0.094 \\
\hline Small hospital & Ref. & & & & & & & & & \\
\hline \multicolumn{11}{|l|}{ Designation effect } \\
\hline Specialty hospital & -0.088 & $<0.0001$ & -0.076 & $<0.0001$ & -0.010 & 0.013 & 0.961 & 0.679 & 0.000 & 0.884 \\
\hline Tertiary hospital & 0.024 & $<0.0001$ & 0.023 & $<0.0001$ & 0.001 & 0.827 & 1.062 & 0.148 & 0.720 & 0.168 \\
\hline Mid-sized hospital & 0.001 & 0.836 & 0.004 & 0.241 & -0.003 & 0.459 & 1.073 & 0.105 & 0.866 & 0.538 \\
\hline \multicolumn{11}{|l|}{ DEA efficiency } \\
\hline Efficient & -0.020 & 0.529 & 0.228 & $<0.0001$ & -0.241 & $<0.0001$ & 0.977 & 0.508 & 0.556 & 0.064 \\
\hline Non-efficient & Ref. & & & & & & & & & \\
\hline \multicolumn{11}{|l|}{ Geographic } \\
\hline Metropolitan area & 0.021 & 0.184 & 0.060 & 0.001 & -0.038 & 0.054 & 0.994 & 0.792 & 0.948 & 0.521 \\
\hline Non-metropolitan area & Ref. & & & & & & & & & \\
\hline \multicolumn{11}{|l|}{ Teaching status } \\
\hline Teaching & 0.048 & 0.039 & 0.023 & 0.232 & 0.026 & 0.256 & 0.801 & $<0.0001$ & 1.072 & 0.567 \\
\hline Non-teaching & Ref. & & & & & & & & & \\
\hline Number of beds $(\times 100)$ & -0.007 & 0.125 & -0.004 & 0.395 & -0.004 & 0.460 & 1.014 & $<0.0001$ & 1.003 & 0.801 \\
\hline Number of specialists per 100 beds & -0.005 & $<0.0001$ & 0.004 & $<0.0001$ & -0.009 & $<0.0001$ & 1.020 & $<.0001$ & 1.004 & 0.609 \\
\hline Number of nurses per 100 beds & -0.001 & $<0.0001$ & 0.001 & 0.000 & -0.003 & $<0.0001$ & 0.998 & $<0.0001$ & 1.004 & 0.099 \\
\hline Bed occupancy rate & 0.002 & $<0.0001$ & 0.001 & 0.635 & 0.002 & $<0.0001$ & 1.000 & 0.672 & 0.998 & 0.483 \\
\hline
\end{tabular}


mortality were not statistically significant. This 'designation effect' was not noted for either readmission or mortality outcome. Efficient hospitals were more likely to follow the trend of spine specialty hospitals in terms of charging and LOS. Males were associated with higher charges per case and per day, but shorter LOS. Patients with higher CCL scores had higher charges per case and longer LOS. Hospitals located in metropolitan areas had higher charges per case and shorter LOS. Teaching hospitals had higher charges per case but no significant difference in charge per day or LOS when compared with non-teaching hospitals. Hospital structural factors also were associated with outcome variables; however, the effects were minimal.

\section{DISCUSSION}

In this study, we investigated the performance and efficiency of spine specialty hospitals versus general hospitals and examined the effect of 'specialty' hospital designation on hospital operating efficiency. Our data set included spine specialty hospital designation criteria and nationwide inpatient claims in South Korea. Our univariate results showed that charges per inpatient case were lower and LOS were much shorter for specialty hospitals; however, per day charges were higher than other hospitals with the exception of tertiary hospitals. The results of multivariate analysis, after adjusting for patient-level and hospital-level confounders, showed that while spine specialty hospital charges on a per case basis were similar to those of small general hospitals, the per day charges were $27.4 \%$ higher; however, the higher per day charge was balanced by $23.5 \%$ shorter LOS. Following 'specialty' hospital designation, inpatient charges per case declined by $6.6 \%$, because of shorter LOS $(1.0 \%)$ and lower per day charges $(7.6 \%)$ than general hospitals of comparable size.

Although this study considered only short-term effects of the 'specialty' designation, spine specialty hospitals appeared to be motivated to reduce their charges. This effect suggests that spine specialty hospitals increased their efficiencies because of their spine specialisation and resulting positive volume outcome relationship. ${ }^{23} 24$ Therefore, these hospitals were able to reduce overall costs and charge less than other hospitals. This finding also indicates that the 'specialty hospital' designation influenced spine specialty hospitals to reduce the financial burden on their patients.

Our findings also revealed that specialty hospitals had much shorter LOS for each spine inpatient. This result supports the premise that specialty hospital physicians have more experience due to their sheer volume, which also allows the specialty hospital to emphasise efficiency by reducing LOS. Shorter LOS for the specialty hospitals was superior to small, mid-sized general hospitals and also was better than tertiary hospitals. However, higher per day charges indicated that specialty hospitals ensure financial viability via high volume and bed turnover. In order to be designated a specialty hospital in Korea, an institution must meet strict institutional requirements, including having a certain number of beds and physicians in addition to operating a specialty medical service department. This process requires a substantial investment by the institution. Since no additional reimbursements or financial subsidies for specialty hospitals exist, this might only be a marketing strategy, ensuring the institution's financial viability by increasing its efficiency. In addition, the results of our study also provide empirical research confirming the arguments of opponents of specialty hospitals, who contend that specialty hospitals may provide healthcare services at greater profit or cherry pick patients more than traditional hospitals. ${ }^{6} 17 \quad 1820$ A higher proportion of low CCL patients and surgery rate may support propositions of opponents.

Furthermore, specialty hospitals are most commonly located in metropolitan areas and therefore incur high rent, payroll and other operating costs. Therefore, the overall operating costs for specialty hospitals are often higher than those for hospitals that are located in nonmetropolitan areas. ${ }^{25}$ This demographic would suggest that specialty hospitals offset their high operating costs by charging more per day for a shorter LOS, thus increasing patient volume and bed turnover. DEA results also indicated that in order for hospitals to achieve operational efficiency, they might have shorter LOS $(24.1 \%)$ and higher charge per day (22.8\%) than non-efficient hospitals, although charge per case is similar. This finding supports the trend observed for higher specialty hospital efficiency with regard to patient charges and LOS.

Comparing quality measures between specialty hospitals and small general hospitals of similar size, readmission within 30 days of discharge was $20 \%$ lower $(\mathrm{OR}=0.796)$ in spine specialty hospitals but was similar to larger hospitals (mid-sized, tertiary hospitals). This quality measure might be better in spine specialty hospitals because of their higher patient volume and much vaster medical experience in the area of spine disease. However, we did not find any association with mortality within 30 days of admission to spine specialty hospitals. We would expect very few cases of mortality among all types of hospitals since spine disease procedures typically are not life-threatening. Of note, our study was only able to evaluate in-hospital mortality, which might underestimate actual mortality cases.

This study has several limitations worth considering; therefore, the results must be interpreted with caution. The potential limitation of our study involves our measurement of the effect of 'specialty' designation status. Because of the relatively recent establishment of the specialty hospital designation system (1 November 2011), there has not been sufficient time to thoroughly investigate the effects of the 'specialty' designation on hospital operating efficiency. Additional studies using more robust data sets should be performed to better inform long-term policy on spine specialty hospitals. Furthermore, this study may not fully adjust case-mix adjustment, although the analysis models 
include current diagnosis and procedure code, due to the nature of claims data. In addition, we did not have access to information about non-NHI covered procedures, which is important because non-covered services are typical in spine-related procedures. Our study also lacked patient satisfaction records or socioeconomic status data that may have affected the results of our study. ${ }^{26}$

The other limitation was the inability to analyse hospital financial performance. Because we did not include institutions' financial statements or costs, it was not possible to examine the real financial viability of hospitals. Therefore, the actual revenue, costs, profit and financial viability and their possible impact on our results remain unknown.

Although our study involved only spine-related inpatient claim data, it represents, to the best of our knowledge, one of only a few studies to evaluate the performance and characteristics of specialty hospitals in this country and outside the USA as well. Our conclusions add to the mounting evidence about the greater efficiency and cost benefits of specialty hospitals; these results contribute to the reasoning for designing 'specialty' designation requirements and implementing specialty hospital systems in a health policy perspective. In order to strengthen the reliability and generalisability of our findings, additional studies investigating the effect of 'specialty' designation status over a longer time frame are needed.

\section{CONCLUSION}

In conclusion, our study showed that spine specialty hospitals have higher per day inpatient charges and much shorter LOS than other types of hospitals due to their specialty volume and experience. Specialty hospitals endeavour to be more efficient after governmental 'specialty' designation. In addition, the patient readmission rate was lower for specialty hospitals than general hospitals. To promote a successful specialty hospital system, a broader discussion that includes patient satisfaction and the real cost of care should be initiated.

\section{Author affiliations \\ ${ }^{1}$ Department of Public Health, Yonsei University College of Medicine, Seoul, South Korea \\ ${ }^{2}$ Institute of Health Services Research, Yonsei University College of Medicine, Seoul, South Korea \\ ${ }^{3}$ Department of Medicine, University of Wisconsin School of Medicine and Public Health, Milwaukee, Wisconsin, USA \\ ${ }^{4}$ Center for Senior Health and Longevity, Aurora Health Care, Milwaukee, Wisconsin, USA \\ ${ }^{5}$ Department of Hospital Administration, Graduate School of Public Health, Yonsei University, Seoul, South Korea \\ ${ }^{6}$ Department of Preventive Medicine, Yonsei University College of Medicine, Seoul, South Korea}

Contributors SJK designed the study, researched data, performed statistical analyses and wrote the manuscript. JWY, SGL, THK, K-TH and E-CP contributed to the discussion, and reviewed and edited the manuscript. E-CP is the guarantor.

Competing interests None.

Provenance and peer review Not commissioned; externally peer reviewed.
Data sharing statement No additional data are available.

Open Access This is an Open Access article distributed in accordance with the Creative Commons Attribution Non Commercial (CC BY-NC 4.0) license, which permits others to distribute, remix, adapt, build upon this work noncommercially, and license their derivative works on different terms, provided the original work is properly cited and the use is non-commercial. See: http:// creativecommons.org/licenses/by-nc/4.0/

\section{REFERENCES}

1. OECD. OECD reviews of health care quality. OECD Publishing, 2012.

2. Kwon S. Payment system reform for health care providers in Korea Health Policy Plan 2003;18:84-92.

3. Lee KS, Chun KH, Lee JS. Reforming the hospital service structure to improve efficiency: urban hospital specialization. Health Policy 2008:87:41-9.

4. Ministry of Health and Welfare. http://stat.mw.go.kr [In Korean].

5. Kim J. Hospital performance and their foster plan. Seoul: Korean Institute of Hospital Management, 2005.

6. Iglehart JK. The emergence of physician-owned specialty hospitals. N Engl J Med 2005;352:78-84.

7. Carey K, Burgess JF Jr, Young GJ. Specialty and full-service hospitals: a comparative cost analysis. Health Serv Res 2008;43:1869-87.

8. Al-Amin M, Zinn J, Rosko MD, et al. Specialty hospital market proliferation: strategic implications for general hospitals. Health Care Manage Rev 2010;35:294-300.

9. Barro JR, Huckman RS, Kessler DP. The effects of cardiac specialty hospitals on the cost and quality of medical care. J Health Econ 2006;25:702-21.

10. Mitchell JM. Utilization changes following market entry by physician-owned specialty hospitals. Med Care Res Rev 2007;64:395-415.

11. Swartzmeyer S, Killoran C. Specialty hospital ban was premature. Studies would have shown whether those facilities help or harm healthcare. Mod Healthc 2004;34:21

12. Herzlinger R. Specialty Hospitals, Ambulatory Surgery Centers, and General Hospitals: Charting a Wise Public Policy. Conference held on September 10; Washington DC. Waltham, MA: Council on Health Care Economics and Policy, 2004.

13. Porter ME, Teisberg EO. Redefining competition in health care. Harv Bus Rev 2004;82:64-76, 136.

14. Casalino LP, Devers KJ, Brewster LR. Focused factories? Physician-owned specialty facilities. Health Aff 2003;22:56-67.

15. Medicare Payment Advisory Commission. Report to the Congress: physician-owned specialty hospitals, 2005.

16. United States General Accounting Office. Specialty hospitals: geographic location, services provided, and financial peformance. Washington DC: 2003.

17. Moore K, Coddington D. Specialty hospital rise could add to full-service hospital woes. Healthc Financ Manage 2005;59:84

18. Nallamothu BK, Rogers MA, Chernew ME, et al. Opening of specialty cardiac hospitals and use of coronary revascularization in medicare beneficiaries. JAMA 2007;297:962-8.

19. Kahn CN III. Intolerable risk, irreparable harm: the legacy of physician-owned specialty hospitals. Health Aff (Millwood) 2006;25:130-3.

20. American Hospital Association. Impact of limited-service providers on communities and full-service hospitals trendwatch. Trendwatch 2004;6:1-8.

21. Korean Hospital Association. Hospital Management Statistics. 2011.

22. Charnes A, Clark CT, Cooper W, et al. A developmental study of data envelopment analysis in measuring the efficiency of maintenance units in the US air forces. Ann Oper Res 1984;2:95-112.

23. Tsugawa $\mathrm{Y}$, Kumamaru $\mathrm{H}$, Yasunaga $\mathrm{H}$, et al. The association of hospital volume with mortality and costs of care for stroke in Japan. Med Care 2013;51:782-8.

24. Coté GA, Imler TD, $\mathrm{Xu} \mathrm{H}$, et al. Lower provider volume is associated with higher failure rates for endoscopic retrograde cholangiopancreatography. Med Care 2013;51:1040-7.

25. Kim SJ, Park EC, Jang SI, et al. An analysis of the inpatient charge and length of stay for patients with joint diseases in Korea: specialty versus small general hospitals. Health Policy 2013;113:93-9.

26. Perelman J, Closon MC. Impact of socioeconomic factors on in-patient length of stay and their consequences in per case hospital payment systems. J Health Serv Res Policy 2011;16:197-202. 